PUBLIK: Jurnal Manajemen Sumber Daya Manusia, Adminsitrasi dan Pelayanan Publik Sekolah Tinggi Ilmu Administrasi Bina Taruna Gorontalo Volume VIII Nomor 1, 2021

\title{
KEPUASAN PENGGUNA LAYANAN PUBLIK PADA UNIT KERJA BADAN LAYANAN UMUM (BLU) BIDANG PENDIDIKAN
}

\author{
Arif Kurniawan $^{1}$; Dani Sugiri² \\ Politeknik Keuangan Negara STAN \\ arifkurniawan@gmail.com ${ }^{1}$; danisugiri@pknstan.ac.id ${ }^{2}$
}

\begin{abstract}
ABSTRAK
Penelitian ini bertujuan mengukur Indeks Kepuasan Masyarakat (IKM) sebagai indikator kinerja pelayanan Fakultas Ilmu Sosial (FIS) sebagai unit kerja BLU Universitas Negeri Yogyakarta (UNY). Penelitian dilakukan dengan pendekatan kuantitatif deskriptif berdasarkan instrumen IKM yang diatur dalam Permenpan RB Nomor 14 Tahun 2017. Penelitian menggunakan data sampel sebanyak 353 mahasiswa yang diambil dari populasi 3.012 mahasiswa FIS UNY. Satuan kerja pemerintah dapat menerapkan Pola Pengelolaan Keuangan Badan Layanan Umum (BLU) dengan tujuan untuk mengoptimalkan kinerja dan pelayanan kepada masyarakat. Hasil penelitian menunjukkan bahwa IKM FIS UNY dalam kategori baik. Aspek persyaratan; waktu penyelesaian layanan; biaya atau tarif; spesifikasi produk dan jenis layanan; serta sarana prasarana dalam kategori baik. Sedangkan aspek sistem mekanisme dan prosedur; kompetensi pelaksana; perilaku pelaksana; serta penanganan pengaduan saran dan masukan masih dalam kategori kurang baik. Responden memberikan saran agar dilakukan perbaikan terutama untuk aspek-aspek yang masih kategori kurang baik.
\end{abstract}

Kata Kunci: Indeks Kepuasan Masyarakat; Layanan; Badan Layanan Umum

\section{ABSTRACT}

This study aims to measure the Community Satisfaction Index (IKM) as an indicator of the service performance of the Faculty of Social Sciences (FIS) as the BLU work unit of Yogyakarta State University (UNY). The research was conducted with a descriptive quantitative approach based on the IKM instrument regulated in Permenpan RB Number 14 of 2017. The study used a sample of 353 students taken from a population of 3,012 students of FIS UNY. Government agenciescan apply the Public Service Agency (BLU) Financial Management Pattern with the aim of optimizing performance and services to the community. The results showed that IKM FIS UNY was in good category. Aspect requirements; service turnaround time; fees or rates; product specifications and types of services; as well as infrastructure in good category. Meanwhile, aspects of the mechanism and procedure systems; executive competence; implementing behavior; as well as the handling of complaints, suggestions and input are still in the poor category. Respondents provide suggestions for improvement, especially for aspects that are still in poor category.

Keywords: Community Satisfaction Index; Service; Public Service Agency

\section{PENDAHULUAN}

Administrasi publik telah mengalami perkembangan yang berarti, dari awalnya sekedar administrasi publik tradisional (traditional public administration) menjadi the new 
PUBLIK: Jurnal Manajemen Sumber Daya Manusia, Adminsitrasi dan Pelayanan Publik Sekolah Tinggi Ilmu Administrasi Bina Taruna Gorontalo Volume VIII Nomor 1, 2021

public management, dan terakhir menjadi the new public service (Denhardt \& Denhardt, 2003). Transformasi tersebut menempatkan peran pemerintah yang berbeda dalam memperlakukan dan mengarahkan masyarakat. Perubahan tata kelola organisasi pemerintah telah mempengaruhi pemahaman masyarakat tentang bagaimana layanan yang adil harus diberikan (Andrews \& Van de Walle, 2013). Tuntutan masyarakat mengenai perlu dilakukannya perbaikan kinerja birokrasi pelayanan publik telah menjadi wacana sampai saat ini (Mardiastuti, 2015). Tuntutan masyarakat untuk perbaikan birokrasi berkaitan rendahnya kualitas pelayanan publik, berprilaku korup dan nepotism (KKN), adanya kecenderungan untuk memusatkan kewenangan, masih rendahnya profesionalisme, dan tidak terdapatnya budaya dan etika pelayanan yang baik (Jufri, 2019). Menghadapi perubahan masyarakat dewasa ini, organisasi publik harus memastikan bahwa isu-isu utama manajemen harus (a) melakukan pengelolaan risiko dan ketidakpastian, (b) mengenalkan bisnis dengan cara-cara yang agile, (c) memperhatikan perbedaan ras dan mencegah terjadinya inklusivisme, (d) mendorong pemberian layanan, (e) mewujudkan keamanan sekuritas, dan (f) mendorong operasi yang berwawasan keberlanjutan lingkungan (Gerton \& Mitchell, 2019).

Layanan organisasi pemerintah ke publik di bidang pendidikan mendapatkan perhatian yang cukup tinggi. Hal ini karena layanan pendidikan dinikmati hampir seluruh lapisan masyarakat dan mendapatkan dukungan pendanaan yang besar dari pemerintah. Hal ini sejalan dengan UUD 1945 amandemen keempatPasal 31 Ayat 4 yang mengamanatkan kewajiban pemerintah untuk mengalokasikan biaya pendidikan sekurang-kurangnya $20 \%$ dari APBN maupun APBD agar masyarakat dapat menikmati pelayanan pendidikan (Undang-Undang Dasar Negara Republik Indonesia Tahun 1945 Amandemen I-IV, 1945). Dalam kurun waktu tahun 2016 sampai dengan tahun 2021, alokasi anggaran pendidikan terus naik dari jumlah Rp.370,8 triliun hingga 549,5 triliun (Kementerian Keuangan RI, 2020). Pengalokasian anggaran pendidikan yang cukup besar diharapkan akan berbanding lurus dengan meningkatnya kualitas dan layanan pendidikan yang akan dimanfaatkan oleh masyarakat (Arifah, 2018). Oleh karena itu, pengelolaan unit penyelenggaraan pendidikan dengan tata kelola yang sehat menjadi penting.

Untuk mengoptimalkan kinerja organisasi pemerintah, satuan kerja pemerintah saat ini dapat mengadopsi praktik pengelolaan dan bisnis yang sehat dengan menerapkan Pola Pengelolaan Keuangan Badan Layanan Umum (BLU). Dalam Peraturan Pemerintah Nomor 23 tahun 2005, disebutkan bahwa BLU merupakan instansi di lingkungan pemerintah yang dibentuk untuk memberikan pelayanan kepada masyarakat berupa penyediaan barang dan/atau jasa yang dijual tanpa mengutamakan mencari keuntungan dan dalam melakukan 
PUBLIK: Jurnal Manajemen Sumber Daya Manusia, Adminsitrasi dan Pelayanan Publik Sekolah Tinggi Ilmu Administrasi Bina Taruna Gorontalo Volume VIII Nomor 1, 2021

kegiatannya didasarkan pada prinsip efisiensi dan produktivitas (Peraturan Pemerintah Nomor 23 Tahun 2005 Tentang Pengelolaan Keuangan Badan Layanan Umum, 2005). BLU kini telah tumbuh cukup pesat baik di pemerintah pusat maupun di pemerintah daerah, terutama untuk BLU di bidang pendidikan dan kesehatan, termasuk salah satunya Universitas Negeri Yogyakarta (UNY).

Sebagai organisasi publik, BLU dihadapkan pada tuntutan peningkatan kualitas pelayanan. Everard dalam Wicaksono (2011) menyatakan bahwa kualitas layanan merupakan tercapai atau terpenuhinya harapan pengguna layanan. Dalam dunia pendidikan, maka layanan pendidikan yang berkualitas dapat dilihat dari terpenuhinya harapan konsumen yaitu mahasiswa. Mendengarkan suara pelanggan adalah penghargaan terhadap kebebasan menyuarakan pendapat. Mengedepankan demokrasi atau mendengarkan pendapat orang lain adalah ciri utama dalam New Public Service (Denhardt \& Denhardt, 2003).

Kementerian Keuangan melalui Direktorat Jenderal Perbendaharaan telah menetapkan indikator kinerja yang dapat digunakan untuk mengukur kualitas BLU bidang pendidikan. Kepuasan pelanggan menjadi salah satu indikator penilaian kinerja pada aspek pelayanan BLU. Peraturan Dirjen Perbendaharaan Nomor PER-21/PB/2015 mengamanatkan bahwa kepuasan pelanggan diukur dengan Indeks Kepuasan Masyarakat (IKM). IKM yang dimaksud dalam PER-21/PB/2015 tersebut merujuk pada IKM yang diatur dalam Peraturan Menteri PAN dan RB Nomor 14 Tahun 2017. Indikator yang digunakan dalam pengukuran IKM meliputi sembilan kriteria yaitu persyaratan, sistem mekanisme dan prosedur, waktu penyelesaian, biaya/tarif, spesifikasi produk dan jenis pelayanan, kompetensi pelaksana, perilaku pelaksana, penanganan pengaduan saran dan masukan, serta sarana prasarana.Namun demikian, BLU Universitas Negeri Yogyakarta belum melaksanakan survei sesuai dengan Permenpan RB Nomor 14 Tahun 2017.

Terdapat lima dimensi berupa bukti fisik, empati, reabilitas, kecepatan dan keterjaminan berpengaruh positif terhadap kualitas layanan (Dewi, 2016). Menurut Fikriet al. (2016) dan Syakur (2018), terdapat pengaruh yang kuat dan positif antara kualitas layanan terhadap loyalitas pelanggan pada suatu perguruan tinggi.Abdullah et al. (2013) melakukan penelitian dengan menggunakan tangibles, reliability, responsiveness, assurance, dan empathy untuk menganalisis kualitas pelayanan terhadap mahasiswa Fakultas Ekonomi Universitas Negeri Yogyakarta (UNY). Yuniarti (2014) melakukan penelitian sejenis untuk mengukur kepuasan mahasiswa pada Program Ekstensi Fakultas Ekonomi Universitas Jambi. Kualitas pelayanan mempunyai hubungan positif dan signifikan dengan kepuasan mahasiswa (Wicaksono, 2011). Menurut Wendha et. Al (2013) 
PUBLIK: Jurnal Manajemen Sumber Daya Manusia, Adminsitrasi dan Pelayanan Publik Sekolah Tinggi Ilmu Administrasi Bina Taruna Gorontalo Volume VIII Nomor 1, 2021

dan Syakur (2018), kepuasan pelanggan merupakan kunci dalam menciptakan loyalitas pelanggan. Fornell dalam Aryani \& Rosinta (2010), menyebutkan bahwa kepuasan pelanggan dapat mencegah terjadinya perputaran pelanggan, mengurangi sensitivitas pelanggan terhadap harga, mengurangi biaya kegagalan pemasaran, serta meningkatkan reputasi bisnis.

BLU Pendidikan memiliki tuntutan perbaikan kinerja yang cukup besar. Pertama, sebagai badan layanan umum sebagai bentuk enterpresing governmentyang merupakan praktik ril dari semangat New Public Management dan The New Public Service (Pujiningsih, 2015). Kedua, posisi sebagai tempat akamedis atau tempat pendidikan. Gerton \& Mitchell (2019) menyebutkan bahwa akademik era sekarang mempunyai peran sebagai penginspirasi aksi, pemaham mendalam atas suatu isu, penghubung antar pemangku kepentingan, serta pendorong perubahan.

Sebagai unit kerja di UNY, Fakultas Ilmu Sosial (FIS) juga menjadi bagian dari penyukses target dan tuntutan masyarakat akan kinerja BLU UNY. Untuk itu, pada tahun 2019, FIS telah melakukan survei kepuasan mahasiswa. Survei tersebut dilakukan dengan melihat tiga aspek utama yaitu: (1) layanan kemahasiswaan, (2) proses pendidikan, serta (3) pengelolaan keuangan, sarana dan prasarana. Survei ini dilakukan dengan sistem daring melalui alamat www.survei.uny.ac.id. Pada survei tersebut terdapat 414 mahasiswa FIS UNY yang menjadi responden.

Hasil survei tersebut ditunjukkan sebagaimana dalam Tabel 1.

Tabel 1 Rata-rata Penilaian Survei Per Bidang Layanan FIS UNY

\begin{tabular}{|c|l|r|}
\hline No. & \multicolumn{1}{|c|}{ Aspek Layanan } & Nilai \\
\hline 1. & Layanan kemahasiswaan & 3,11 \\
\hline 2. & Proses pendidikan & 3,28 \\
\hline 3. & Pengelolaan keuangan, sarana, dan prasarana & 3,38 \\
\hline
\end{tabular}

Sumber: LPPM UNY (2020)

Namun demikian, survei tersebut belum sesuai dengan maksud pengukuran kepuasan pelanggan yang diamanatkan oleh Permenpan RB Nomor 14 Tahun 2017 tentang Pedoman Penyusunan Survei Kepuasan Masyarakat Unit Penyelenggara Pelayanan Publik. PermenPAN RB tersebut menggunakan pendekatan Indeks Kepuasan Masyarakat (IKM). Permenpan RB Nomor 14 Tahun 2017 merupakna pengganti atas Keputusan MenPAN Nomor 25 tahun 2004. Indeks Kepuasan Masyarakat (IKM) sendiri merupakan salah satu metode yang digunakan untuk menentukan kualitas pelayanan publik lewat persepsi masyarakat (Nesimnasi et al., 2019). IKM dalam Permenpan RB Nomor 14 Tahun 2017 dihitung dengan menggunakan nilai persepsi yang dikonversi untuk mengetahui mutu 
PUBLIK: Jurnal Manajemen Sumber Daya Manusia, Adminsitrasi dan Pelayanan Publik Sekolah Tinggi Ilmu Administrasi Bina Taruna Gorontalo Volume VIII Nomor 1, 2021

pelayanan dan kategori nilai. Tabel 2 menyajikan kriteria penilaian kepuasan masyarakat menurut IKM.

Tabel 2 Kriteria Penilaian Kepuasan Masyarakat

\begin{tabular}{|c|c|c|c|c|}
\hline NilaiPersepsi & Nilai Interval & Nilai Interval Konversi & Mutu Pelayanan & Kategori Nilai \\
\hline 1 & $1,00-2,5996$ & $25,00-64,99$ & D & Tidak Baik \\
\hline 2 & $2,60-3,064$ & $65,00-76,60$ & C & Kurang Baik \\
\hline 3 & $3,0644-3,532$ & $76,61-88,30$ & B & Baik \\
\hline 4 & $3,5324-4,00$ & $88,31-100,00$ & A & Sangat Baik \\
\hline
\end{tabular}

Sumber: PermenPAN Nomor 14 Tahun 2017 (2017)

Penelitian pengukuran kepuasan pengguna layanan dengan IKM telah dilakukan oleh beberapa peneliti. Putra (2012) melakukan pengukuran IKM untuk pelayanan Puskesmas Tegalrejo, namun dengan menggunakan 14 kriteria yang ditetapkan dalam Keputusan MenPAN Nomor 25 tahun 2004.Mardiastuti (2015) juga melakukan pengukuran IKM pada Unit Referensi Perpustakaan UGM. Penelitian pengukuran IKM pernah dilakukan Subandi \& Pratama (2018) untuk mengetahui kualitas layanan publik Dinas Perhubungan Kabupaten Kutai Kartanegara khususnya layanan uji berkala kendaraan bermotor dan layanan angkut sungai. Indikator berdasarkan ketentuan tersebut juga digunakan Damayanti et al., (2019) ketika mengukur persepsi dan kepuasan masyarakat atas pelayanan Kecamatan Sawan Kabupaten Buleleng.Sedangkan Nesimnasi et al. (2019) menggunakan IKM untuk mengukur kualitas pelayanan pada Puskesmas Oepoi Kota Kupang. Namun demikian, penelitian-penelitian tersebut tidak dilakukan untuk mengkonfirmasi atas hasil metode pengukuran lain untuk kepuasan pengguna layanan pada objek yang sama.

Penelitian ini dimaksudkan untuk melihat capaian kualitas pelayanan pendidikan yang diselenggarakan oleh salah satu unit kerja di BLU UNY dalam perspektif pelanggan. Penilaian capaian kualitas layanan menggunakan ukuran kepuasan pengguna layanan berupa Indeks Kepuasan Masyarakat (IKM) sebagaimana dimaksudkan dalam Permenpan RB Nomor 14 tahun 2017.

Penelitian dimaksudkan untuk mengetahui tingkat kepuasan mahasiswa sebagai pengguna layanan di FIS UNY dengan menggunakan kriteria IKM yaitu aspek persyaratan, sistem mekanisme dan prosedur, waktu penyelesaian, biaya/tarif, spesifikasi produk dan jenis pelayanan, kompetensi pelaksana, perilaku pelaksana, penanganan pengaduan saran dan masukan, serta sarana prasarana. Kriteria IKM dipilih karena merupakan ukuran kepuasan pengguna layanan yang direkomendasikan oleh pemerintah. Selain itu penelitian juga dimaksudkan untuk melihat aspek-aspek yang perlu dibenahi dalam penyediaan layanan oleh FIS UNY.

\section{METODE PENELITIAN}

Penelitian dilakukan dengan pendekatan kuantitatif dengan maksud mengambil generalisasi hasil penelitian kepada keseluruhan populasi mahasiswa FIS UNY. Data yang digunakan merupakan data primer dari sampel mengenai persepsi atas layanan yang 
PUBLIK: Jurnal Manajemen Sumber Daya Manusia, Adminsitrasi dan Pelayanan Publik Sekolah Tinggi Ilmu Administrasi Bina Taruna Gorontalo Volume VIII Nomor 1, 2021

diterima saat mengikuti pendidikan di FIS UNY. Pengambilan sampel dilakukan secara random sampling. Variabel dalam kuesioner menggunakan variabel dan konstruk yang direkomendasikan oleh Permenpan RB Nomor 14 Tahun 2017.Pengolahan data dilakukan dengan menggunakan formula perhitungan Indeks Kepuasan Masyarakat (IKM). Tabel 3 menyajikan kisi-kisi instrumen kueisoner yang digunakan dalam penelitian.

Tabel 3. Kisi-Kisi Instrumen Kuesioner

\begin{tabular}{|c|l|c|}
\hline No. & \multicolumn{1}{|c|}{ Unsur } & Jumlah Butir \\
\hline 1 & Persyaratan & 5 \\
\hline 2 & Sistem mekanisme dan prosedur & 1 \\
\hline 3 & Waktu penyelesaian & 1 \\
\hline 4 & Biaya/tarif & 3 \\
\hline 5 & Produk spesifikasi dan jenis pelayanan & 1 \\
\hline 6 & Kompetensi pelaksana & 1 \\
\hline 7 & Perilaku pelaksana & 1 \\
\hline 8 & Penanganan pengaduan saran dan masukan & 15 \\
\hline 9 & Sarana prasarana & \\
\hline
\end{tabular}

\section{HASIL PENELITIAN}

Dengan populasi mahasiswa FIS UNY sebesar 3.012 mahasiswa. Berdasarkan Krejcie dan Morgan, dengan populasi sebesar itu, diperlukan sampel minimal sebanyak 341 mahasiswa. Sampel dipilih secara acak (random sampling) di antara mahasiswa tingkat pertama sampai dengan tingkat akhir. Pada survei ini, disebarkan sebanyak 380 kuesioner kepada mahasiswa FIS UNY yang dipilih secara random sampling. Terdapat 369 kuesioner yang diisi oleh mahasiswa. Setelah diteliti kembali, terdapat 16 kuesioner yang tidak diisi secara lengkap oleh mahasiswa, sehingga hanya terdapat lembar kuesioner yang terisi dengan lengkap sebesar 353 orang. Tabel 4 menyajikan ringkasan hasil survei dari 353 responden tersebut.

Hasil survei menunjukkan bahwa lima unsur menunjukkan kategori nilai baik dan empat unsur menunjukkan kategori nilai kurang baik. Lima unsur yang menunjukkan kategori baik adalah unsur persyaratan; unsur waktu penyelesaian; unsur biaya atau tarif; unsur produk, spesifikasi, dan jenis pelayanan; serta unsur sarana prasarana. Empat unsur yang menunjukkan kategori kurang baik adalah unsur sistem mekanisme dan prosedur; unsur kompeten sipelaksana; unsur perilaku pelaksana; serta unsur penanganan pengaduan saran dan masukan. 
PUBLIK: Jurnal Manajemen Sumber Daya Manusia, Adminsitrasi dan Pelayanan Publik Sekolah Tinggi Ilmu Administrasi Bina Taruna Gorontalo Volume VIII Nomor 1, 2021

Tabel 4.Hasil Survei Mahasiswa FIS UNY

\begin{tabular}{|c|c|c|c|c|c|c|}
\hline Unsur & Nilai & $\begin{array}{c}\text { Nilai } \\
\text { dasar } 25\end{array}$ & Mutu & $\begin{array}{c}\text { Kategori } \\
\text { Nilai }\end{array}$ & SKM & Ікм \\
\hline Persyaratan & 3,24 & 81,08 & B & Baik & 9,01 & \multirow{9}{*}{77,04} \\
\hline $\begin{array}{l}\text { Sistem mekanis } \\
\text { me dan prosedur }\end{array}$ & 3,04 & 76,06 & $\mathrm{C}$ & $\begin{array}{c}\text { Kurang } \\
\text { Baik }\end{array}$ & 8,45 & \\
\hline $\begin{array}{l}\text { Waktu penyele } \\
\text { saian }\end{array}$ & 3,13 & 78,19 & B & Baik & 8,69 & \\
\hline Biaya atau tarif & 3,15 & 78,82 & B & Baik & 8,76 & \\
\hline $\begin{array}{l}\text { Produk, } \\
\text { spesifikasi, dan } \\
\text { jenis pelayan } \\
\text { an }\end{array}$ & 3,10 & 77,50 & B & Baik & 8,61 & \\
\hline $\begin{array}{l}\text { Kompe } \\
\text { tensi pelaksa } \\
\text { na }\end{array}$ & 3,05 & 76,13 & $\mathrm{C}$ & $\begin{array}{c}\text { Kurang } \\
\text { Baik }\end{array}$ & 8,46 & \\
\hline $\begin{array}{l}\text { Perilaku pelaksa } \\
\text { na }\end{array}$ & 3,02 & 75,57 & $\mathrm{C}$ & $\begin{array}{c}\text { Kurang } \\
\text { Baik }\end{array}$ & 8,40 & \\
\hline $\begin{array}{l}\text { Penanganan } \\
\text { pengaduan saran } \\
\text { dan masukan }\end{array}$ & 2,86 & 71,39 & $\mathrm{C}$ & $\begin{array}{c}\text { Kurang } \\
\text { Baik }\end{array}$ & 7,93 & \\
\hline $\begin{array}{l}\text { Sarana pra } \\
\text { sarana }\end{array}$ & 3,14 & 78,60 & B & Baik & 8,73 & \\
\hline
\end{tabular}

Sumber: Diolah Penulis, 2020.

Berdasarkan olahan data yang terkumpul, indeks kepuasan masyarakat (IKM) dari FIS UNY adalah sebesar 76,61. Secara umum nilai tersebut termasuk dalam kategori kinerja baik. Akan tetapi masih terdapat beberapa hal yang perlu diperhatikan. Unsur sistem mekanisme dan prosedur, kompetensi pelaksana, perilaku pelaksana, serta penanganan pengaduan saran dan masukan termasuk dalam kategori kurang baik menjadi beberapa unsur yang masih perlu diperhatikan. Begitu juga unsur sarana dan prasarana meskipun mendapatkan nilai dalam kategori baik. Akan tetapi unsur ini masih membutuhkan perhatian pada beberapa butir di dalam unsur tersebut.

\section{Unsur Persyaratan.}

IKM untuk unsur persyaratan sebesar 81,08 dan termasuk dalam kategori baik. Persyaratan tersebut adalah syarat dalam pengurusan jenis layanan tertentu, baik yang bersifat teknis maupun administratif yang harus dipenuhi. Unsur persyaratan dinilai dengan lima pernyataan terkait dengan (a) kejelasan struktur organisasi, (b) disampaikannya 
PUBLIK: Jurnal Manajemen Sumber Daya Manusia, Adminsitrasi dan Pelayanan Publik Sekolah Tinggi Ilmu Administrasi Bina Taruna Gorontalo Volume VIII Nomor 1, 2021

struktur organisasi tersebut di laman resmi, (c) adanya rencana strategis, (d) adanya monitoring dan evaluasi terhadap rencana strategis, serta (e) kesesuaian antara persyaratan layanan dengan persyaratan yang disampaikan oleh petugas. Dari kelima hal tersebut, aspek terendah pada aspek d, dimana terdapat ketidaksesuaian antara yang disampaikan petugas dengan ketentuan persyaratan layanan.

\section{Unsur Mekanisme dan Prosedur.}

IKM untuk unsur sistem mekanisme dan prosedur adalah sebesar 76,06 dan termasuk dalam kategori kurang baik. Sistem mekanisme dan prosedur berkaitan dengan tata cara atau aturan yang harus dilaksanakan oleh penerima maupun pemberi layanan. Mahasiswa mengeluhkan seringnya terjadi pergantian prosedur layanan dan mereka berharap setiap pembaruan prosedur operasional standar dapat disosialisasikan lebih awal. Kampus harus bertanggungjawab terhadap implementasi sistem, mekanisme dan prosedur yang telah ditetapkan. Tanggungjawab kampus atas implementasi terbuat akan berpengaruh terhadap kepuasan mahasiswa sesuai penelitian Wicaksono (2011).

\section{Unsur Waktu Pelayanan.}

IKM untuk unsur waktu pelayanan adalah sebesar 78,19 dan termasuk dalam kategori baik. Unsur waktu pelayanan berkaitan dengan kesesuaian antara jangka waktu yang diperlukan untuk menyelesaikan suatu layanan di FIS UNY sdengan jam layanan yang telah ditentukan. Namun demikian, mahasiswa menyarankan agar fakultas bisa lebih mendisiplinkan jam layanan. Hal ini karena beberapa kali didapati pegawai layanan tidak berada di tempat layanan pada saat jam layanan berlangsung. Temuan ini sejalan dengan penelitian Andrews \& Van de Walle (2013) yang menyatakan bahwa persepsi masyarakat memiliki hubungan negatif dengan hubungan pemerintah-swasta di Inggris. Hal ini berarti wajar bahwa masyarakat masih memiliki ekspektasi lebih dari layanan yang sediakan. Perlunya dilakukan upaya penanaman pemahaman kepada para petugas untuk selalu memberikan pelayanan yang cepat, tepat atau akurat dan berkeadilan (Bagou, 2020).

\section{Unsur Biaya/Tarif.}

IKM untuk unsur biaya/tarif adalah sebesar 78,82 dan termasuk dalam kategori baik. Unsur biaya/tarif berkenaan dengan ongkos yang harus dibayarkan oleh penerima layanan yaitu mahasiswa untuk memperoleh pelayanan. Unsur biaya/tarif dinilai telah sesuai antara biaya layanan yang ditetapkan dengan biaya layanan yang dibayarkan. Namun demikian, terdapat responden yang mengeluhkan bahwa uang kuliah tunggal (UKT) dirasa cukup besar, sehingga mereka merasa membutuhkan keringanan.

\section{Unsur Produk Spesifikasi dan Jenis Layanan.}

IKM untuk unsur produk spesifikasi dan jenis pelayanan mendapatkan nilai 77,50 dan termasuk dalam kategori baik. Unsur ini berkaitan dengan (a) kesesuaian hasil layanan yang diterima oleh pengguna layanan dengan ketetapan yang ada, (b) terlaksananya rencana pembelajaran dengan baik, serta (c) kemutakhiran materi yang diberikan oleh dosen. Dua item aspek yang mendapatkan penilaian terendah adalah aspek b dan c. Beberapa mahasiswa menyoroti beberapa dosen yang tidak memiliki dasar keilmuan tertentu tetapi 
PUBLIK: Jurnal Manajemen Sumber Daya Manusia, Adminsitrasi dan Pelayanan Publik Sekolah Tinggi Ilmu Administrasi Bina Taruna Gorontalo Volume VIII Nomor 1, 2021

justru mengampu mata kuliah yang memerlukan dasar keilmuan tersebut. Maturbongs (2019) menyarankan agar perguruan tinggi harus mempersiapkan SDM memiliki 4 komponen keilmuan yaitu (a) mampu mengubah mindset dan talent; (b) humanis; (c) terampil dalam pemanfaatan sarana dan prasarana di era revolusi industri 4.0, dan; (d) memiliki kompetensi teknis praktis.

Hasil pengukuran tersebut sangat bermanfaat dalam pengembangan pelayanan FIS UNY ke depan. Hasil ini survei ini dapat mendorong FIS UNY dapat melakukan perbaikan sejalan dengan pendapat Gerton \& Mitchell (2019) yang menginginkan kampus menjadi penghubung yang baik antar pemangku kepentingan, serta pendorong perubahan. Pemangku kepentingan kampus tidak hanya berkaitan hubungan kampus dengan pihak lain, terlebih dari itu memperhatikan tata hubungan dengan mahasiswa adalah penting, karena mahasiswa adalah pengguna layanan utama. Dorongan perubahan diarahkan untuk menemukan inovasi-inovasi baru, mempromosikan praktik yang lebih efektif, mengidentifikasi cara dan mendorong solusi, serta membangunan rencana aksi serta menindaklanjuti rekomendasi (Gerton \& Mitchell, 2019).

\section{KESIMPULAN}

Pengukuran kepuasan pengguna layanan FIS UNY belum menggunakan instrumen survei kepuasan berdasarkan Permenpan RB Nomor 14 Tahun 2017. Survei yang dilakukan oleh FIS UNY tahun 2019 dilakukan hanya mencakup aspek layanan kemahasiswaan; proses pendidikan; pengelolaan keuangan, sarana dan prasarana. Sedangkan survei kepuasan menurut Permenpan RB Nomor 14 Tahun 2017 seharusnya mencakup aspek persyaratan; sistem mekanisme dan prosedur; waktu penyelesaian; biaya/tarif; produk, spesifikasi, dan jenis pelayanan; kompetensi pelaksana; perilaku pelaksana penanganan pengaduan saran dan masukan; serta sarana dan prasarana.

Berdasarkan survei yang dilakukan penulis dengan pendekatan unsur-unsur pelayanan dalam Permenpan RB Nomor 14 Tahun 2017, diperoleh hasil IKM sebesar 75,98 atau termasuk dalam kategori baik. IKM tersebut terbentuk dari sembilan unsur. Unsurunsur pelayanan yang mendapatkan kategori baik adalah unsur pelayanan; waktu penyelesaian; biaya/tarif; spesifikasi dan jenis pelayanan; serta sarana dan prasarana. Sedangkan unsur yang mendapatkan kategori kurang baik adalah unsur sistem mekanisme dan prosedur; kompetensi pelaksana; perilaku pelaksana; serta penanganan pengaduan saran dan masukan.

Untuk perbaikan pelayanan FIS UNY disarankan agar FIS UNY berfokus pada aspek atau unsur dengan nilai terendah yaitu penanganan pengaduan saran dan masukan; disusul dengan perilaku pelaksana serta sistem mekanisme dan prosedur. Perbaikan dapat dilakukan antara lain dengan mengimplementasikan sistem pengaduan secara daring yang dapat dipantau tindak lanjutnya, peningkatan kompetensi pelayanan pegawai khususnya terkait komunikasi, serta penyediaan media sosialisasi sistem mekanisme dan prosedur yang mudah diakses dan diketahui civitas akademika FIS UNY. 
PUBLIK: Jurnal Manajemen Sumber Daya Manusia, Adminsitrasi dan Pelayanan Publik Sekolah Tinggi Ilmu Administrasi Bina Taruna Gorontalo Volume VIII Nomor 1, 2021

Pada penelitian selanjutnya, dapat dikembangkan pengukuran kepuasan pelanggan dengan menggunakan metode lain seperti model Parasuraman dan Service Quality in Higher Education (SQHE). Penelitian selanjutnya dapat mempertimbangkan pengukuran lebih luas pada tingkat universitas dan atau melibatkan stakeholder eksternal.

\section{DAFTAR PUSTAKA}

Andrews, R., \& Van de Walle, S. (2013). New Public Management and Citizens' Perceptions of Local Service Efficiency, Responsiveness, Equity and Effectiveness. Public Management Review, 15(5), 762-783. https://doi.org/10.1080/14719037.2012.725757.

Arifah, U. (2018). Kebijakan Publik Dalam Anggaran Pendidikan. Cakrawala: Jurnal Manajemen Pendidikan, 2(1), 17-37. http://ejournal.iainukebumen.ac.id/index.php/cka/article/view/37.

Aryani, D., \& Rosinta, F. (2010). Pengaruh kualitas layanan terhadap kepuasan pelanggan dalam membentuk loyalitas pelanggan. Cakrawala: Jurnal Manajemen Pendidikan Islam Dan Studi Sosial, 17(2), 114-126.

Bagou, U. (2020). Kualitas Pelayanan Kartu Pencari Kerja di Dinas Tenaga Kerja, Koperasi dan Usaha Kecil Menengah Kota Gorontalo. Publik: Jurnal Manajemen Sumber Daya Manusia, VII(1), 10-18. https://doi.org/https://doi.org/10.37606/publik.v7i1.117.

Damayanti, L. D., Suwena, K. R., \& Haris, I. A. (2019). Analisis Kepuasan Masyarakat Terhadap Pelayanan Publik Berdasarkan Indeks Kepuasan Masyarakat (Ikm) Kantor Kecamatan Sawan Kabupaten Buleleng. Jurnal Pendidikan Ekonomi Undiksha, 11(1), 21-32. https://doi.org/10.23887/jjpe.v11i1.20048.

Denhardt, R. B., \& Denhardt, J. V. (2003). The new public service: An approach to reform. International Review of Public Administration, 8(1), 3-10. https://doi.org/10.1080/12294659.2003.10805013.

Dewi, M. (2016). Pengaruh Kualitas Pelayanan terhadap Kepuasan Pasien Pengguna BPJS pada Rumah Sakit Rehabilitasi Medik Kabupaten Aceh Timur. Jurnal Manajemen Dan Keuangan Unsam, 5(2), 535-544. https://www.ejurnalunsam.id/index.php/jmk/article/view/79.

Fikri, S., Wiyani, W., \& Suwandaru, A. (2016). Pengaruh kualitas pelayanan terhadap kepuasan dan loyalitas mahasiswa. Jurnal Bisnis Dan Manajemen, 3(1), 120-134. http://jurnal.unmer.ac.id/index.php/jbm/article/view/80/21.

Gerton, T., \& Mitchell, J. P. (2019). Grand challenges in public administration: Implications for public service education, training, and research. Journal of Public Affairs Education, 25(4), 435-440. https://doi.org/10.1080/15236803.2019.1689780. 
PUBLIK: Jurnal Manajemen Sumber Daya Manusia, Adminsitrasi dan Pelayanan Publik Sekolah Tinggi Ilmu Administrasi Bina Taruna Gorontalo Volume VIII Nomor 1, 2021

Jufri. (2019). Birokrasi dan Upaya Meningkatkan Pelayanan Publik. Kanwil Kemenag Bengkulu. https://bengkulu.kemenag.go.id/opini/314-birokrasi-dan-upayameningkatkan-pelayanan-publik.

Kementerian Keuangan RI. (2020). Buku II Nota Keuangan RAPBN TA 2021. Pemerintah RI.

PermenPAN Nomor 14 Tahun 2017 tentang Pedoman Penyusunan Survei Kepuasan Masyarakat, (2017).

Mardiastuti, A. (2015). Evaluasi Terhadap Kualitas Pelayanan Publik Melalui Kajian Indeks Kepuasan Masyarakat (IKM) pada Unit Referensi Perpustakaan Universitas Gadjah Mada. Berkala Ilmu Perpustakaan Dan Informasi, XI(1), 1-8. https://doi.org/https://doi.org/10.22146/bip.8835.

Maturbongs, Y. H. (2019). E-Learning sebagai Strategi Pengembangan Pendidikan Tinggi. TarFomedia, 43-57. http://www.jurnal.stikstarakanita.ac.id/index.php/forum/article/download/331/200.

Nesimnasi, V., Romeo, P., \& Ndoen, E. M. (2019). Indeks Kepuasan Masyarakat (IKM) terhadap Kualitas Pelayanan Publik di Puskesmas Oepoi Kota Kupang. Lontar: Journal of Community Health, 1(4), 147-154. https://doi.org/10.35508/ljch.v1i4.2180.

Peraturan Pemerintah Nomor 23 Tahun 2005 tentang Pengelolaan Keuangan Badan Layanan Umum, (2005).

Pujiningsih, S. (2015). Public Service Agency (Badan Layanan Umum) of State University as a Model of NPM in Indonesia: Habermasian Perspective. Research Journal of Finance and Accounting, 6(16), 111-117. https://citeseerx.ist.psu.edu/viewdoc/download?doi=10.1.1.876.6771\&rep=rep1\&type $=$ pdf.

Putra, Y. S. (2012). Analisis Indeks Kepuasan Masyarakat (IKM) Terhadap Pelayanan Publik di Puskesmas Tegalrejo Kota Salatiga Tahun 2012. Among Makarti, 7(10), 14-41. https://doi.org/http://dx.doi.org/10.52353/ama.v5i2.130.

Undang-Undang Dasar Negara Republik Indonesia Tahun 1945 Amandemen I-IV, IV 1 (1945).

Subandi, M., \& Pratama, H. E. (2018). Kegiatan Penelitian Analisis Indeks Kepuasan Masyarakat ( IKM ) terhadap Pelayanan Publik Dinas Perhubungan Kabupaten Kutai Kartanegara dilakukan pada unit layanan uji berkala kendaraan bermotor pada Unit Pelaksana Teknis Pengujian Kendaraan Bermotor di T. Jurnal Ilmu Sosial MAHAKAM, 7(1), 27-37. https://ejurnal.unikarta.ac.id/index.php/mahakam/article/view/542/429. 
PUBLIK: Jurnal Manajemen Sumber Daya Manusia, Adminsitrasi dan Pelayanan Publik Sekolah Tinggi Ilmu Administrasi Bina Taruna Gorontalo Volume VIII Nomor 1, 2021

Syakur, A. (2018). Hubungan Kualitas Pelayanan Terhadap Kepuasan Mahasiswa Dan Loyalitas Mahasiswa Ditinjau Dari Model Pembelajaran Di Akademi Farmasi Surabaya. Reformasi, 8(2), 100. https://doi.org/10.33366/rfr.v8i2.1091.

Taman, A., Sukirno, S., Sari, A. R., Setiawan, N., \& Pustikaningsih, A. (2013). Analisis Kualitas Pelayanan Terhadap Kepuasan Mahasiswa Pada Fakultas Ekonomi Universitas Negeri Yogyakarta. Nominal, Barometer Riset Akuntansi Dan Manajemen, 2(1), 99-111. https://doi.org/10.21831/nominal.v2i1.1651.

Wendha, A. P., Rahyuda, K., \& Suasana, I. G. (2013). Pengaruh Kualitas Layanan Terhadap Kepuasan dan Loyalitas Pelanggan Garuda Indonesia di Denpasar. Jurnal Manajemen, Strategi Bisnis Dan Kewirausahaan, 7(1), 19-28. https://ocs.unud.ac.id/index.php/jmbk/article/view/6066.

Wicaksono, D. (2011). Hubungan antara kualitas pelayanan dan tanggung jawab dengan kepuasan pelanggan Fakultas Ilmu Sosial UNJ. Jurnal Manajemen Pendidikan, 2(2), 299-307. http://journal.unj.ac.id/unj/index.php/jmp/article/view/2449/1879.

Yuniarti, Y. (2014). Pengaruh Kualitas Pelayanan terhadap Kepuasan Mahasiswa Program Ekstensi Fakultas Ekonomi Universitas Jambi. Jurnal Ekonomi Trikonomika, 13(1), 49-61. https://doi.org/http://dx.doi.org/10.23969/trikonomika.v13i1.484. 